\title{
Experiment: Make Binding Forces Visible- Molecular Binding Forces, Recycling/Reuse, Life Cycle Engineering (LCE)
}

\author{
Peter Eyerer* \\ Fraunhofer Institute Chemical Technology, Karlsruhe, Germany
}

Submission: July 30, 2020; Published: August 26, 2020

*Corresponding author: Peter Eyerer, Fraunhofer Institute Chemical Technology, Karlsruhe, Germany

Abstract

A very simple experiment shows students the difference between primary and secondary molecular binding forces. Use an empty plastic cup for milk, yoghurt or coffee and destroy it by pressing the cup together. You will watch cracks only longitudinal the cup. Try to break the cup horizontally you will fail. What you observe are the secondary binding forces between the molecules oriented along the length of the cup versus the primary binding forces perpendicular to the long side of cup.

Keywords: Molecular Binding Forces; Recycling/Reuse; Life Cycle Engineering (LCE)

\section{Introduction}

\section{What should be found/investigated?}

[answer: Are the primary molecular binding forces (within the molecular chain acting binding forces, i.e. between primarily connected atoms) actually significantly stronger than the secondary binding forces (between molecules acting forces)? How can a yoghurt cup be reused in a cup of the same application without violating high hygiene regulations in Germany? What role has Life Cycle Engineering for product developers play in the industry? For answers: Students should examine a yoghurt or milk cup.] [1,2].

\section{Why/what could this be important for?}

[answer: The shelf life of packaging helps to mechanically preserve food and make it durable for longer. If the digestion breaks easily, e.g. when falling down, damage to the goods and dirt occur. With this experiment, the students understand how the processing of plastics influences the product properties, how to basics of chemistry i.e. binding forces can be easily (and surprisingly) make visible and tangible and how to intelligently understand recycled material in food packaging (for hygienic reasons almost impossible!).]

\section{Why is the experiment essential for the participants?}

[answer: We all use plastic packaging and throw them away carelessly after use. Mostly we are still annoyed about the voluminous amounts of garbage. And we are surprised how much brain lard and unexpected highly interesting effects, however, are often stuck in such "worthless" products.]

\section{First Experiment}

\section{What is being done?}

\section{[answer:}

a. Each student brings a large (0.5 l) empty cleaned yoghurt or milk plastic cup

b. Each student brings a small $(0.25$ or 0.3 or 0.51$)$ empty cleaned PET bottle

c. The cup and the bottle are squeezed at the top of the edge (cup) or at its whole body (bottle). ]

\section{What happens?}

[answer: The cup breaks into the ground in longitudinal cracks; further crushing leads to longitudinal strips via cracks. The PET bottle does not break!]

Why does the cup break this way? Why does such a strip not break transversely to the longitudinal direction? Not, if you bend over 20x or more often vigorously back and forth?

[solution: the cup was deep drawn below the plastic melting temperature or injection molded above the melting temperature; 
the macromolecules are as a result shear forces oriented in the longitudinal direction. When breaking, the majority of the approx. factor 20 - 35 weaker secondary binding forces act between the polymer molecules; while the binding forces in the chain (between the stronger C-C-bindings) are stressed at right angle they guarantee a high strength. ] [3-8].

\section{Second Experiment}

\section{If the students now repeat the same experiment on a} piece cut from the PET bottle and load the plastic strip by $90^{\circ}$ in each direction, what happens then?

[solution: this PET piece from the bottle has equally high strength in both directions. It does not break in any direction of loading!]
Why?

[solution: biaxially oriented films during production result in stretched

macromolecule chains in both directions (offset by $90^{\circ}$ ); this is followed by high primary bonds and correspondingly high strength biaxially. ]

\section{Further Watching}

\section{What is noticeable when the students take a close look at the fracture surfaces of the longitudinal cracks in the yoghurt or milk cups?}

[solution: They detect a three-layering of the approximately $0.4 \mathrm{~mm}$ thick foil wall of the cup. Outside and inside white, in between gray.] (Figure 1).

Figure 1: Partial image on the left: Yoghurt or milk cups, deep-drawn polystyrene (PS) with middle layer of recycled material. On surfaces outside each new product PS for hygienic reasons; Partial image center: If you crush the cup, it only tears in the longitudinal direction; if you burden it across by bending, it does not break! ! Partial image on the right: By deep drawing at approx. $190{ }^{\circ} \mathrm{C}$ from a 3-layer film, macromolecules as a result of shear forces in the tool and "frozen" during cooling; when heating up again to $130{ }^{\circ} \mathrm{C}$ the macromolecules "remember" their entropic favorable ball shape (2nd main law of thermodynamics: greatest clutter (entropy)) and become a foil again.

\section{What is the explanation for this?}

[solution: the outer layers are made of original material, inside is recycled material, so old (unhygienic) plastic of earlier cups, hidden. This is produced by the so-called co-extrusion [9].]

\section{What are the hygienic regulations in Germany/ Europe?}

A short summary will be found in [10]. Plastic packaging producers are well advised to certificate their packaging standards after British Retail Consortium (BRC) of the Institute of Packaging. This is a surrounding standard for quality, hygiene and product safety. Alternatively, the German/European DIN EN 15593 standards is comparable to BRC. In April 2020, the Fraunhofer IVV published an investigation about disruptive smelling in recycling plastic as LD PE and PET [11] which shows still a lot of open questions.

\section{Conclusion}

\section{What should the students learn from this experiment?}

[answer: They are intended to provide an insight into the complexity of today's mass-produced plastic goods. They will also learn about the chemical and mechanical fundamentals of plastics and get an initial idea of engineering. A qualitative discussion about holistic thinking in terms of Life Cycle Engineering (technical, economical, environmental, social) creates awareness of systemic thinking.]

\section{Is there a social aspect to the question?}

[answer: Plastics, their advantages and disadvantages as well as their recycling are an up-to-date theme. In this way, plastics affect a number of important aspects, such as resource consumption, consumer behavior, closed loop economy, Life Cycle 
Engineering, processing and handling materials, environmental protection.]

\section{Are special competences promoted with the experiment?}

[answer: Theory (basics of chemistry) comprehend by hand ; technical understanding; ability of observing; logical engineering thinking; problem-solving behavior; systemic mindset;]

\section{Is the experiment interdisciplinary?}

[answer: Yes: chemistry, technology, materials science, business administration (qualitative), product(food) protection/ hygiene.]

\section{Is this an actual research topic? If so, why?}

[answer: Yes. Safe packaging is an important issue in resource protection and hygiene. Circular economy is technically, economically, environmentally and socially significant.]

\section{Is it a theme of author's own sponsoring organization?}

[answer: Yes.]

\section{Infobox}

\section{Student laboratory}

a. Open Youth Workshop Karlsruhe e. V. (Offene Jugendwerkstatt Karlsruhe e.V.)

b. Fraunhofer ICT, TheoPrax

\section{Contactpersons}

Peter Eyerer, Fraunhofer ICT, Pfinztal, Germany

Dörthe Krause, TheoPrax Foundation, Pfinztal, Germany

\section{Age and type of school of the target group}

From grade 8 of all school types and also for teachers.

\section{Fields}

Chemistry, natural sciences, technique, physics

\section{Time needed}

Approx. 45 minutes

Tags

a. Primary and secondary binding forces

b. Production of packaging products out of plastic

c. Recycling, reuse

d. Closed loop economy

e. Life Cycle Engineering

f. Systemic thinking

\section{Methods}

\section{Didactically leaded research-oriented experiment}

For the solutions of the question/problems there is enough information material (in writing, visual (videos), haptic).

\section{References}

1. Eyerer P (1979-2006) Kunststoffkunde lectures at University Stuttgart, Germany.

2. Eyerer P, Schüle H, Elsner P (2020) Polymer Engineering ( $\left.2^{\text {nd }} E d n\right)$ Springer Berlin, Germany. V 3, pp. 160.

3. Gauri Nigudkar (2018) Chemical Bonding (3)- Covalent Bonding(2)Vbt (2).

4. Molecule.

5. Theories of Chemical Bonding, Chapter 9.

6. (2010) Secondary Chemical Bond.

7. Ravin Narain (2020) Polymer Science and Nanotechnology, ppp. 455473.

8. Georg Schwedt (2013) Experiments on everyday plastics, pp. 164.

9. Coextruded regenerated polystyrene.

10. Certifications for packaging materials.

11. Less disruptive odor in plastic recyclates (2020).

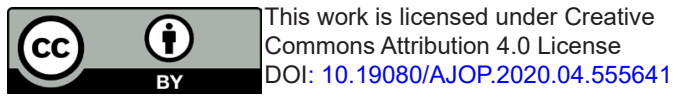

\section{Your next submission with Juniper Publishers} will reach you the below assets

- Quality Editorial service

- Swift Peer Review

- Reprints availability

- E-prints Service

- Manuscript Podcast for convenient understanding

- Global attainment for your research

- Manuscript accessibility in different formats ( Pdf, E-pub, Full Text, Audio)

- Unceasing customer service

Track the below URL for one-step submission https://juniperpublishers.com/online-submission.php 